\title{
CONTRIBUIÇÃO DA PRÁTICA DE EXERCICIOS FISICOS NA QUALIDADE DE VIDA NO TRABALHO: ESTUDO DE CASO DE UMA EMPRESA DO SETOR DE AGRONEGÓCIO
}

\author{
Bruna Tommasini ${ }^{1}$
}

\section{RESUMO}

Este artigo buscou identificar a contribuição da atividade física na Qualidade de Vida no Trabalho. A vida moderna trouxe consigo consequências como sedentarismo e maior ocorrência de L.E.R. - Lesão por Esforço Repetitivo. Cabe às organizações identificar formas de auxiliar os colaboradores a encontrar o equilíbrio entre os diversos fatores que influenciam a Qualidade de vida para que este esteja mais satisfeito e tenha uma maior produtividade. O artigo é um estudo de caso por meio de questionários aplicado em 108 colaboradores de diversos departamentos e níveis hierárquicos. O resultado da pesquisa apontou que $51 \%$ dos colaboradores não fazem atividades físicas devido à jornada de trabalho, estudo (faculdade) e preguiça. Entre os que fazem atividade foram identificados benefícios como maior disposição para o dia-a-dia, redução de estresse, melhoria do sono e da autoestima, demonstrando assim que a atividade física contribui positivamente com a Qualidade de Vida no Trabalho. Para aumentar a participação dos colaboradores nas atividades físicas sugeriu-se a empresa a criação de campanhas de redução de peso, campeonatos/torneios para maior uso do campo de futebol, criação de horários e aulas diferenciados na academia.

Palavra-chave: Qualidade de Vida no Trabalho. Atividade física. Sedentarismo.

\section{INTRODUÇÃO}

A era tecnológica que estamos vivendo facilitou muito a vida das pessoas, seja pessoal como também no trabalho, porém trouxe como uma das consequências o aumento do sedentarismo. Estamos cada vez mais acessíveis, muitas vezes estamos em casa, mas estamos à disposição através do celular, tablete e notebooks. A pressão por produtividade é maior e extrapola o ambiente corporativo, sobrando menos tempo para o lazer.

Inúmeros colaboradores têm se queixado quanto aos esforços repetitivos no trabalho, passam muito tempo em uma mesma posição e tem sofrido com a má.

Neste contexto aparece o interesse pelo fator da Atividade Física como forma de atenuar o esforço dispendido na atividade laboral e também como fator de Qualidade de Vida no Trabalho através da melhora na saúde do trabalhador.

Diante do exposto, este artigo buscou avaliar a contribuição da prática de atividades

\footnotetext{
${ }^{1}$ Graduada em Administração pela União do Ensino Superior de Nova Mutum, pós-graduada em MBA Executivo com Ênfase em Gestão Rural e Agronegócio e RH e Práticas Trabalhistas pela Faculdade Arthur Thomas. Endereço: Avenida dos Canários 372 W, Centro, Nova Mutum-MT. Email: bruna.tommasini@hotmail.com 
físicas na qualidade de vida do trabalhador na Vanguarda Agro S.A., uma empresa do ramo do agronegócio com ações negociadas em Bolsa, de forma que a empresa possa usar estes dados como forma de conscientização e amparo para suas ações em torno da Qualidade de Vida no Trabalho.

O artigo foi desenvolvido em duas etapas: revisão bibliográfica e estudo empírico. O estudo empírico consiste em uma pesquisa quantitativa e qualitativa, através da aplicação de questionários, buscando evidenciar objetivos práticos fundamentados em conhecimento científico. Para coleta de informações foram aplicados questionários no escritório corporativo da empresa em Nova Mutum. A seguir apresenta-se o referencial teórico, a descrição metodológica do presente estudo, análise dos resultados e por fim, as considerações finais.

\section{REVISÃO DA LITERATURA}

\subsection{Qualidade de Vida no Trabalho}

Segundo Chiavenato (2006) a Qualidade de Vida no Trabalho (QVT) associa duas visões opostas, onde de um lado estão às reivindicações dos empregados em relação ao bemestar e satisfação no trabalho e de outro o interesse da organização quanto ao efeito da mesma sobre a produtividade e qualidade.

Bowditch e Buono (2004), numa visão mais ampla, definem a Qualidade de Vida no Trabalho como sendo um conjunto de ações voltadas a melhorar a vida no trabalho.

Para França (2004) a Qualidade de Vida no Trabalho está associada a demandas de saúde, lazer e nutrição. Para o administrador ela é uma competência gerencial e para organização a sua competência é de ordem estratégica. É uma atividade permanente, com forte efeito catalisador nas esferas psicossocial e organizacional.

Do ponto de vista de Maximiano (2006) a Qualidade de Vida no Trabalho é um conceito mais amplo que as teorias tradicionais de motivação, pois a QVT é definida sobre um enfoque biopsicossocial, que é uma visão integrada do ser humano, levando em conta assim, não só o seu bem-estar físico, mas também seu bem-estar biológico, psicológico e social. Neste sentido a QVT, em uma visão ética da condição humana, busca identificar e minimizar os vários tipos de riscos ocupacionais, desde a segurança do ambiente físico até o controle do esforço mental exigidos pelas atividades desempenhadas na empresa.

Todos os autores acima concordam que a QVT está ligada ao bem-estar do 
funcionário, e que quanto mais for a satisfação dos funcionários maior será a QVT.

Para Chiavenato (2006) tanto a competitividade organizacional, quanto a qualidade e produtividade, estão intimamente ligados a QVT. E para que os clientes recebam um bom tratamento e fiquem satisfeitos, as empresas devem começar investindo no bem-estar dos funcionários, satisfazendo-os, para que estes transfiram sua satisfação para os produtos e serviços oferecidos pela empresa.

Reforçando Conte (2003) diz que a importância da QVT está no fato de que as pessoas passam oito horas diárias no trabalho, durante, pelo menos, trinta e cinco anos, e chega um momento em que a produtividade diminui. E é nesta hora que surge a QVT que busca recuperar o ânimo do funcionário para que ele alcance uma melhor produtividade no trabalho.

Bom Sucesso (2002) afirma que as pessoas são a verdadeira vantagem competitiva de uma organização, por isso é importante investir em Qualidade de Vida no Trabalho.

Figueira Junior (2004) aponta as hipóteses do ganho de produtividade associado ao investimento na qualidade de vida do trabalhador:

1) Melhor relação do funcionário com a empresa e amigos;

2) Melhor autocontrole para a solução de problemas;

3) Maior poder de concentração e maior resistência psíquica;

4) Redução da ansiedade e aumento das ideias inovadoras;

5) Percepção de "ser importante" para o crescimento da empresa;

6) Maior potencial decisório e paciência na elaboração de estratégias;

7) Melhor bem estar e satisfação pessoal.

Pode-se perceber através dos autores a importância da qualidade de vida no trabalho tanto para a empresa que ganha em produtividade quanto para o trabalhador que se sente mais satisfeito consigo mesmo e com a empresa.

\subsection{Atividade física e Qualidade de Vida no Trabalho}

De acordo com Neto (1994) as pessoas buscam praticar atividade física, pois foi comprovado cientificamente que a atividade física melhora a qualidade de vida, além de que traz melhoras no campo da estética, social, entre outros.

Grüspan (2001) diz que inúmeras empresas identificaram um aumento na satisfação com o trabalho, um melhor desempenho e maior qualidade de vida no trabalho após a inclusão da atividade física na vida de seus colaboradores. 
O artigo de Jackson (1999) apud Figueira Junior (2004) aponta que os diferentes estilos de vida impactam em custos com a saúde dos trabalhadores, conforme abaixo:

1) FUMANTES: $\quad$ Exigem $114 \%$ mais em tempo de internação

Faltam $40 \%$ mais que não fumantes

Custam 26\% mais em despesas com saúde

2) SEDENTÁRIOS: Exigem 54\% mais em tempo de internação

Custam 36\% mais em despesas de saúde

3) OBESOS: $\quad$ Exigem $85 \%$ mais em tempo de internação

Custam $8 \%$ mais em despesas de saúde

Figueira Junior (2004) ainda aponta que:

...empresas que investiram em programas de qualidade de vida e bem estar enfocando programas de fitness (atividades aeróbicas e programas individuais), tabagismo (políticas de desenvolvimento e apoio), redução de lombalgia (prescrição do exercício), nutrição (controle de peso, orientação), stress (tai chi) e aspectos preventivos (mudança de estilo de vida e atividade física), apresentaram modificações positivas na saúde do funcionário e nos fatores ligados ao trabalho e na imagem institucional...

Costa (2000) descreve que segundo pesquisadores a prática de atividade física, feita de forma regular, contribui com a prevenção a prevenção de várias doenças, redução da ansiedade, dentre outros benefícios.

Desta forma, pode-se perceber que a atividade física contribui de forma significativa na qualidade de vida no trabalho, visto que o indivíduo que pratica atividades físicas tem uma melhora na saúde que reflete diretamente na sua disposição para o trabalho.

\section{METODOLOGIA}

A metodologia aplicada foi a de estudo de caso sendo utilizado como base o Escritório Central em Nova Mutum que é a sede da empresa. Os questionários foram elaborados com base no referencial teórico e continham 11 questões, sendo este aplicado através de formulário impresso com todos os colaboradores que estavam no escritório de 22/08 a 28/08, totalizando 108 colaboradores que representam $69,23 \%$ do total.

Buscou-se identificar os funcionários que praticavam atividade física regular e os que não praticavam de forma a analisar seu atual estado físico bem como os motivos de 
praticarem ou não atividade física.

\section{RESULTADOS E DISCUSSÕES}

\subsection{Histórico da Empresa}

A Vanguarda Agro é uma empresa produtora de commodities agrícolas, com foco na produção de soja, milho e algodão e valorização de terras. Possui 13 unidades de produção localizadas em cinco estados brasileiros (Mato Grosso, Goiás, Minas Gerais, Bahia e Piauí), totalizando uma área sob gestão de aproximadamente 253,5 mil hectares.

A companhia é uma sociedade anônima, constituída no Brasil, possuindo o status de Companhia Aberta deferido pela CVM em 9 de novembro de 2006. Em 10 de novembro de 2006, foi realizada a Oferta Pública Inicial de Ações.

É o resultado da incorporação de três empresas: Brasil Ecodiesel, Maeda Agroindustrial (incorporada em dezembro de 2010) e Vanguarda Participações (incorporada em setembro de 2011). As duas últimas empresas, genuinamente agrícolas, consolidaram a estratégia da Companhia de adoção de um novo modelo de negócios com foco na produção de grãos e fibras. Sua transformação operacional e consequentemente sua mudança de denominação social para Vanguarda Agro S.A. ocorreram em 10 de outubro de 2011.

Como decorrência do foco em grãos, a Companhia promoveu um plano continuado de desinvestimento de ativos ligados ao biodiesel para concentrar-se na operação agrícola. Tornou-se uma das Companhias que detém a maior extensão de terras sob gestão do país, além de ser uma das maiores produtoras de grãos e fibras do país listada no Novo Mercado da BMF\&BOVESPA, com ticker code VAGR3. Sua estrutura acionária é pulverizada com predominância majoritária de investidores brasileiros.

\subsection{Resultados da pesquisa - Dados gerais}

Dos participantes da pesquisa 50,93\% não fazem atividade física regular e 49,07\% fazem atividade física regular.

GRÁFICO 01 - DISTRIBUIÇÃO PARTICIPANTES 


\section{Número de Participantes da Pesquisa}

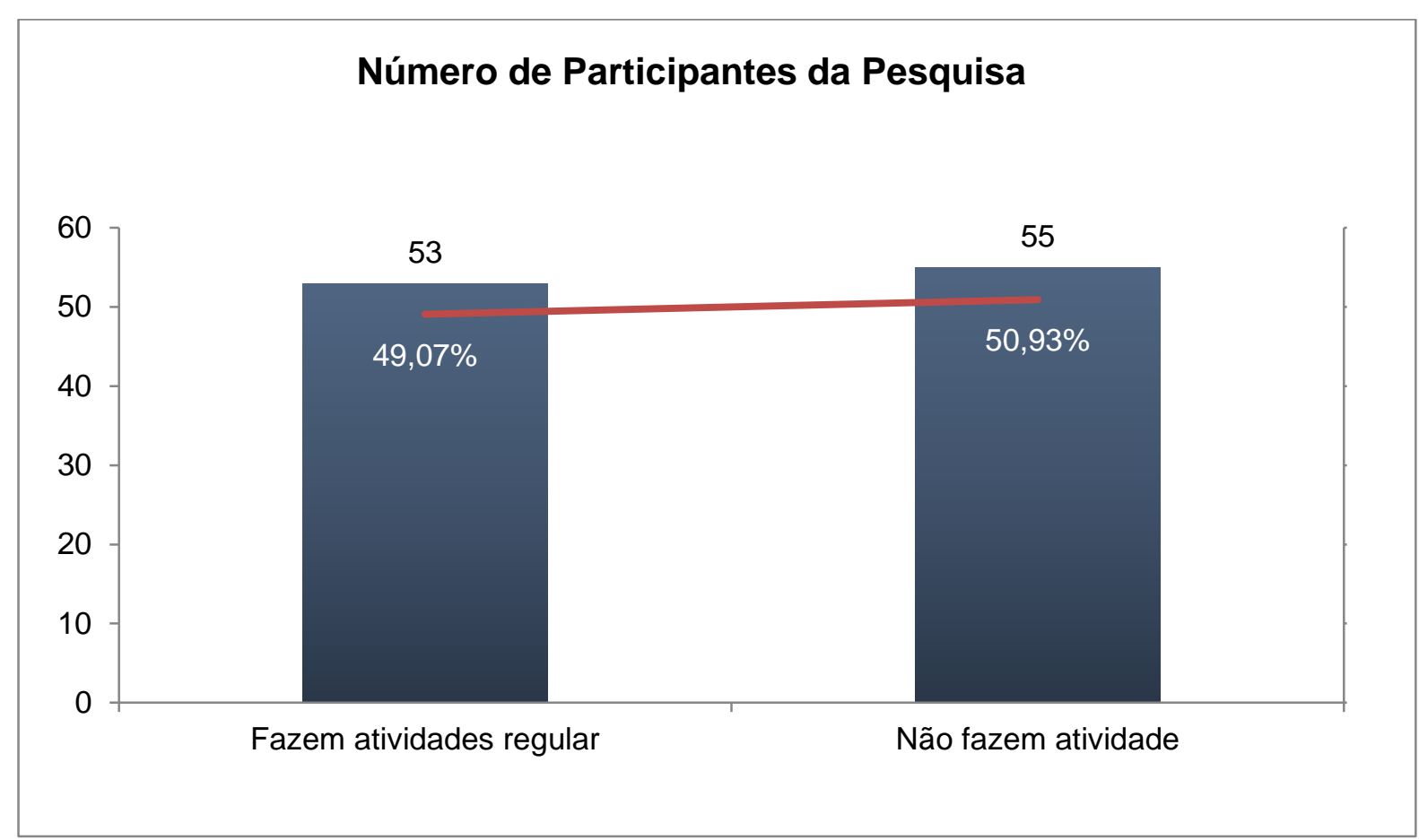

Fonte: Pesquisa de campo Vanguarda Agro S.A, 2014.

O gráfico 02 representa o gênero dos participantes da pesquisa, divididos entre aqueles que fazem atividade física regular e os que não fazem nenhuma atividade física. Entre as mulheres $43,48 \%$ fazem atividade, enquanto $56,25 \%$ delas não fazem nenhuma atividade. Já entre os homens, 53,23\% fazem atividade física e 46,77\% não fazem. Ou seja, os homens praticam mais exercícios físicos que as mulheres. Parte disto pode ser explicado pela jornada dupla que as mulheres vivem que é a vida no trabalho e a vida no lar cuidando dos filhos, marido e da casa.

GRÁFICO 02 - GÊNERO

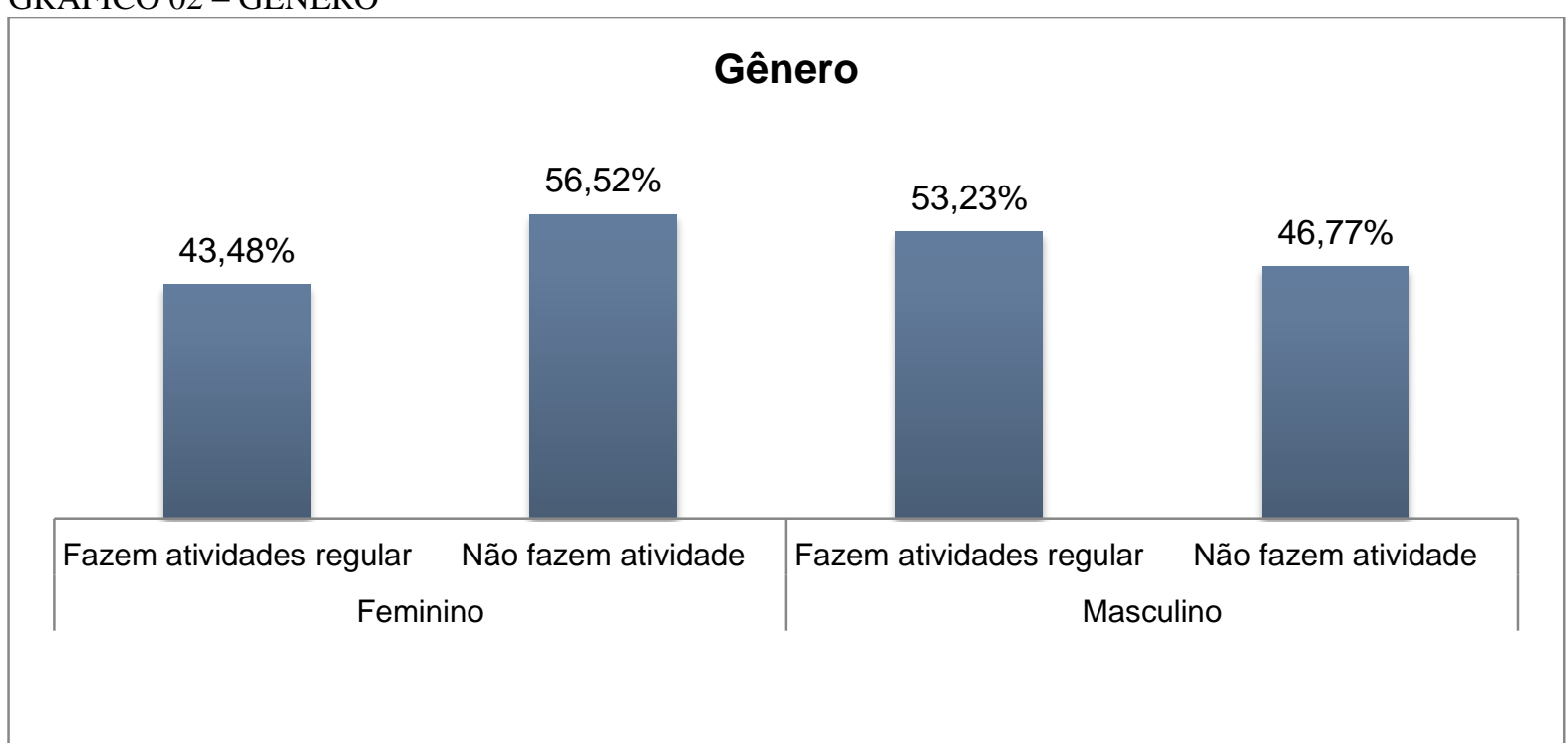

Fonte: Pesquisa de campo Vanguarda Agro S.A, 2014. 
Quanto à idade média, as mulheres que fazem atividade física regular são mais jovens tendo como idade média 26 anos em relação aos 30 anos de média daquelas que não fazem atividade. Já entre os homens a idade média foi a mesma, 31 anos, entre os que fazem atividade e os que não fazem.

\section{GRÁFICO 03 - IDADE MÉDIA}

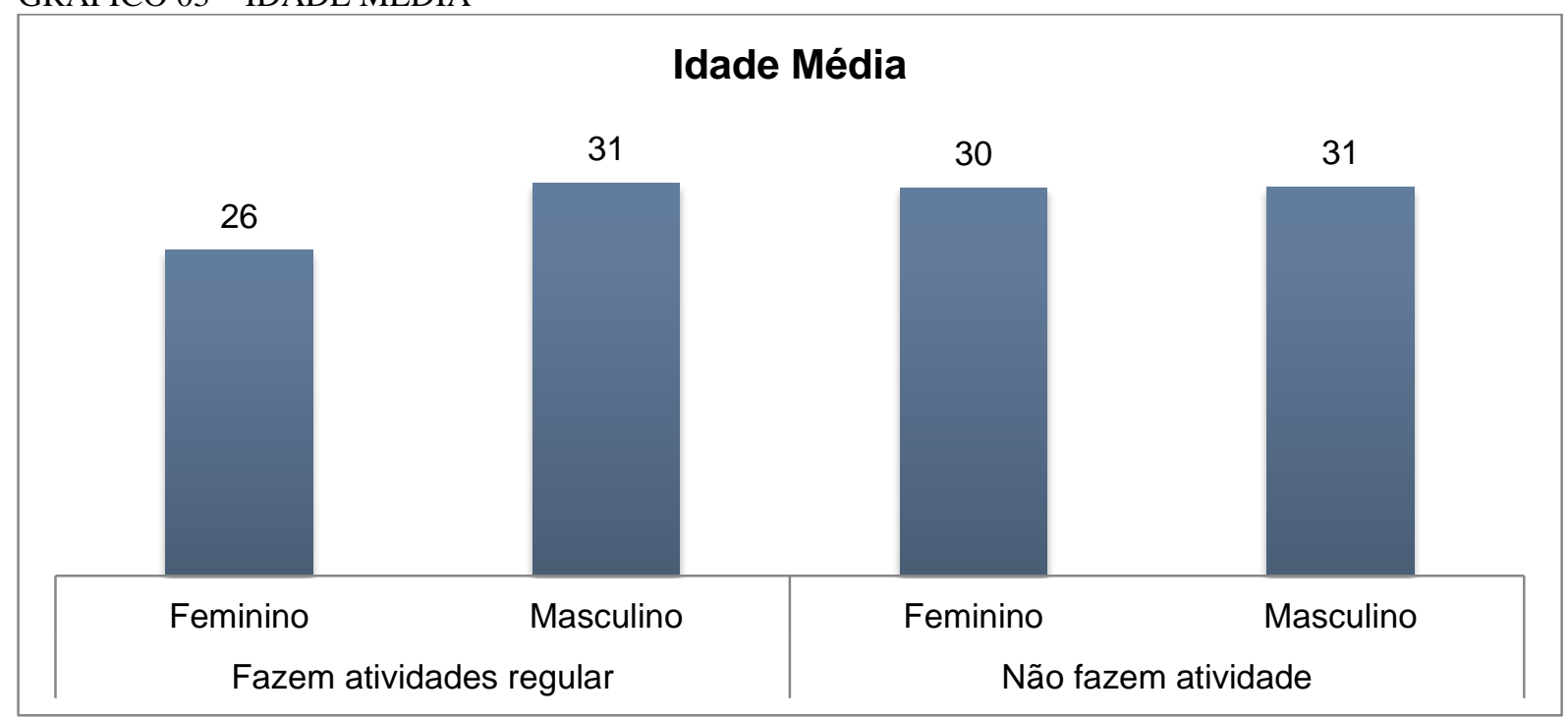

Fonte: Pesquisa de campo Vanguarda Agro S.A, 2014.

Foi perguntado aos colaboradores se o computador é a ferramenta de trabalho principal deles, onde a maioria entre os que fazem atividade física $(98,11 \%)$ e entre os que não fazem atividade física $(92,45 \%)$ respondeu que utilizam o computador como principal ferramenta de trabalho.

GRÁFICO 04 - FERRAMENTA DE TRABALHO 


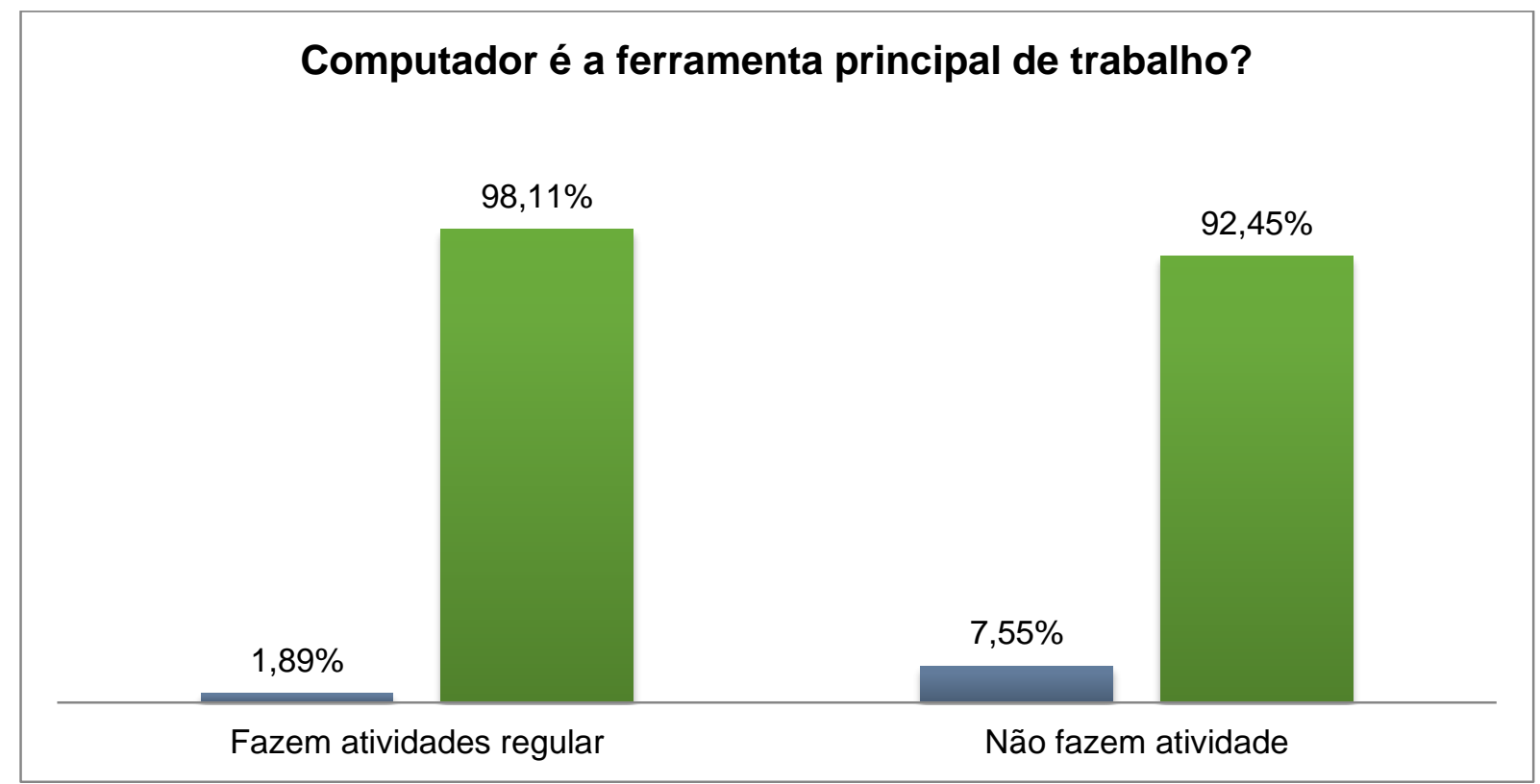

Fonte: Pesquisa de campo Vanguarda Agro S.A, 2014.

Foram feitas também outras perguntas em relação ao estilo de vida da amostra a fim de se identificar fatores relevantes à pesquisa, apresentados pela tabela 01 .

Tabela 1: Estilo de Vida

\begin{tabular}{|c|c|c|c|c|c|c|c|c|}
\hline Pergunta & \multicolumn{2}{|c|}{ Sempre } & \multicolumn{2}{|c|}{ Quase Sempre } & \multicolumn{2}{|c|}{ Raramente } & \multicolumn{2}{|c|}{ Nunca } \\
\hline 1. Sente-se Cansado? & $2 \%$ & $11 \%$ & $30 \%$ & $41 \%$ & $66 \%$ & $48 \%$ & $2 \%$ & $0 \%$ \\
\hline 2. Sente-se satisfeito com seu sono? & $23 \%$ & $20 \%$ & $54 \%$ & $53 \%$ & $17 \%$ & $15 \%$ & $6 \%$ & $13 \%$ \\
\hline 3. Você fuma? & $0 \%$ & $2 \%$ & $2 \%$ & $5 \%$ & $2 \%$ & $2 \%$ & $96 \%$ & $91 \%$ \\
\hline 4. Mantém alimentação saudável? & $10 \%$ & $19 \%$ & $77 \%$ & $65 \%$ & $13 \%$ & $17 \%$ & $0 \%$ & $0 \%$ \\
\hline 5. Sente-se satisfeito com seu corpo/aparência? & $28 \%$ & $19 \%$ & $55 \%$ & $44 \%$ & $9 \%$ & $22 \%$ & $8 \%$ & $15 \%$ \\
\hline 6. Trabalha maior parte do tempo sentado? & $68 \%$ & $70 \%$ & $28 \%$ & $22 \%$ & $2 \%$ & $4 \%$ & $2 \%$ & $4 \%$ \\
\hline
\end{tabular}

Fonte: Pesquisa de campo Vanguarda Agro S.A, 2014.

Com relação à disposição para o dia-a-dia quem faz atividade física sente se menos cansado (68\%), já quem não faz atividade física 52\% sentem-se cansados sempre ou quase sempre. Quanto ao sono $77 \%$ dos que praticam atividade física sentem-se satisfeito com seu sono, enquanto em quem não faz atividade este índice é de $73 \%$.

De acordo com MELLO, BOSCOLO, ESTEVES e TUFIK (2005) diversos estudos científicos tem demonstrado que pessoas ativas, que praticam exercício regularmente apresentam-se menos cansadas devido a melhora do sono e consequente melhora na disposição física. Na empresa pesquisada neste estudo de caso, não foi diferente, aqueles que praticam atividade física tem maior disposição no seu-dia-adia em relação àqueles que não a praticam. 
Segundo diversos autores analisados no artigo de Barros e Santos (2005) o estilo de vida moderno está associado à ocorrência de diversas doenças crônico-degenerativas, doenças psicossomáticas, distúrbios psicológicos e doenças osteomusculares. Este estilo de vida é caracterizado pelo hábito de fumar, dieta inadequada e inatividade física.

Quanto ao tabagismo, o índice de fumantes é maior em quem não pratica atividades físicas $7 \%$ que declararam fumar sempre ou quase sempre. A maioria dos colaboradores declara nunca fumar.

Pode se ver que os que fazem atividade física tem maior satisfação com seu corpo/aparência $83 \%$ frente aos $65 \%$ que se sentem satisfeito com seu corpo sem fazer atividade física.

Miles (2007) apud Santos \& Simões (2012) a melhora na percepção sobre a imagem corporal pode ser relacionada a prática de atividade física como um benefício psicológico associado ao tema, esta sensação de autoestima e bem estar é capaz de reduzir os estados de ansiedade e depressão. Desta forma a atividade física tem grande contribuição sobre a satisfação consigo mesmo.

A pesquisa também apontou que a maioria dos pesquisados trabalham grande parte do tempo na posição sentado ( $96 \%$ dos que praticam atividade física e $92 \%$ dos que não fazem atividade), isto porque a atividade do escritório corporativo é basicamente administrativa, o que contribui para estes altos índices. A empresa realiza hoje a Ginástica Laboral, no período da manhã, todos os dias visando minimizar os efeitos de se trabalhar tanto tempo sentado e também devido aos movimentos repetitivos associados ao uso do computador no exercício de suas atividades laborais. Assim, sugere-se a empresa a continuação destas atividades e também o incentivo e conscientização quanto à importância de se dar uma pausa nas atividades, e se levantar para alongar-se.

A tabela 02 apresenta os dados sobre o atual estado físico na percepção dos colaboradores pesquisados.

Tabela 2: Estado Físico

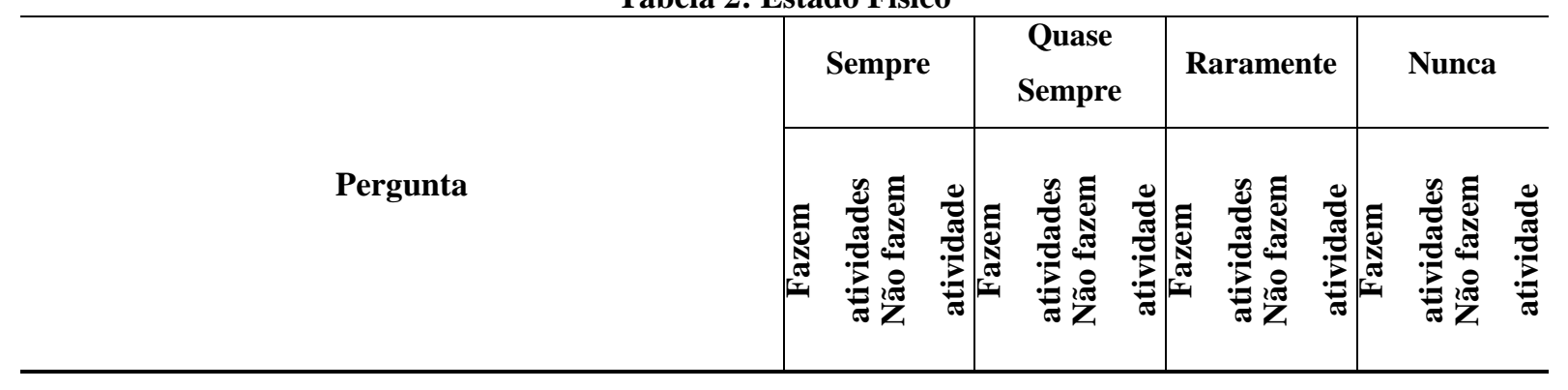

Volume 4, Número 7

Revista UNEMAT de Contabilidade

Jan./Jun. 2015

UNEMAT 


\begin{tabular}{l|cc|cc|cc|c|c} 
3. Sente dores na cabeça por tensão? & $2 \%$ & $9 \%$ & $9 \%$ & $19 \%$ & $57 \%$ & $40 \%$ & $32 \%$ & $32 \%$ \\
$\begin{array}{l}\text { 9. Sinto algum tipo de desconforto nas costas ou } \\
\text { coluna (Lombar). }\end{array}$ & $9 \%$ & $7 \%$ & $25 \%$ & $36 \%$ & $58 \%$ & $49 \%$ & $8 \%$ & $7 \%$ \\
10. Sinto desconforto nos braços e mãos. & $2 \%$ & $0 \%$ & $11 \%$ & $23 \%$ & $60 \%$ & $60 \%$ & $26 \%$ & $17 \%$ \\
$\begin{array}{l}\text { 11. Sinto desconforto nas pernas e pés. } \\
\text { 12. Sinto desconforto no pescoço (cervical). }\end{array}$ & $2 \%$ & $5 \%$ & $8 \%$ & $24 \%$ & $60 \%$ & $47 \%$ & $30 \%$ & $24 \%$ \\
13. Sinto desconforto nos ombros. & $8 \%$ & $11 \%$ & $13 \%$ & $31 \%$ & $47 \%$ & $39 \%$ & $32 \%$ & $19 \%$ \\
$\begin{array}{l}\text { 14. Atualmente sinto desconforto físico geral - dores } \\
\text { musculares. }\end{array}$ & $2 \%$ & $8 \%$ & $13 \%$ & $19 \%$ & $55 \%$ & $53 \%$ & $30 \%$ & $21 \%$ \\
$\begin{array}{l}\text { 15. Utilizo analgésico para dor muscular. } \\
\text { 16. Sinto formigamento nas mãos. }\end{array}$ & $0 \%$ & $5 \%$ & $4 \%$ & $13 \%$ & $36 \%$ & $38 \%$ & $60 \%$ & $44 \%$ \\
17. Sinto dificuldade ao dormir, devido a dores & $0 \%$ & $2 \%$ & $2 \%$ & $4 \%$ & $32 \%$ & $29 \%$ & $66 \%$ & $65 \%$ \\
musculares. & $0 \%$ & $2 \%$ & $4 \%$ & $5 \%$ & $29 \%$ & $25 \%$ & $67 \%$ & $67 \%$ \\
\hline Total & $\mathbf{2 \%}$ & $\mathbf{5 \%}$ & $\mathbf{9 \%}$ & $\mathbf{2 0 \%}$ & $\mathbf{5 0 \%}$ & $\mathbf{4 3 \%}$ & $\mathbf{3 8 \%}$ & $\mathbf{3 2 \%}$ \\
\hline
\end{tabular}

Fonte: Pesquisa de campo Vanguarda Agro S.A, 2014.

Em relação ao estado físico, a tabela mostra que quem não faz atividade física em geral sentem maiores desconfortos físicos em relação com quem pratica exercícios físicos regulares, $29 \%$ de quem não faz atividade física indicam sentir sempre ou quase sempre algum desconforto/uso de remédio contra $11 \%$ em quem faz atividades físicas.

As maiores queixas apresentadas entre os que não fazem atividade física são: desconforto na região cervical (pescoço) com 52\%, depois nas costas ou coluna (região lombar) com $43 \%$ dos pesquisados, seguidos com $29 \%$ com dores nas pernas e pés, depois com $28 \%$ dores na cabeça por tensão e dores musculares em geral e com $27 \%$ aparece desconformo nos ombros.

Entre os que praticam atividades físicas as maiores queixas são: desconforto nas costas ou coluna (região lombar) com $34 \%$, depois na região cervical (pescoço) com $21 \%$ dos pesquisados, seguidos com 15\% com dores/desconforto nos ombros, depois com 13\% dores nos braços e mãos e $11 \%$ dores na cabeça por tensão.

Desta forma pode-se entender que aqueles que praticam atividade física sentem menos desconforto físico, concluindo-se então que a atividade física contribui positivamente para o bem-estar físico.

\subsection{Resultados específicos dos colaboradores não praticantes de atividades físicas}


Foi direcionada uma pesquisa aos que não praticam atividade física para geração de dados para a área de Saúde da Companhia de forma a auxiliar na gestão das ferramentas disponíveis.

Primeiramente foi perguntado por que eles não praticam atividades físicas.

\section{GRÁFICO 04 - FERRAMENTA DE TRABALHO}

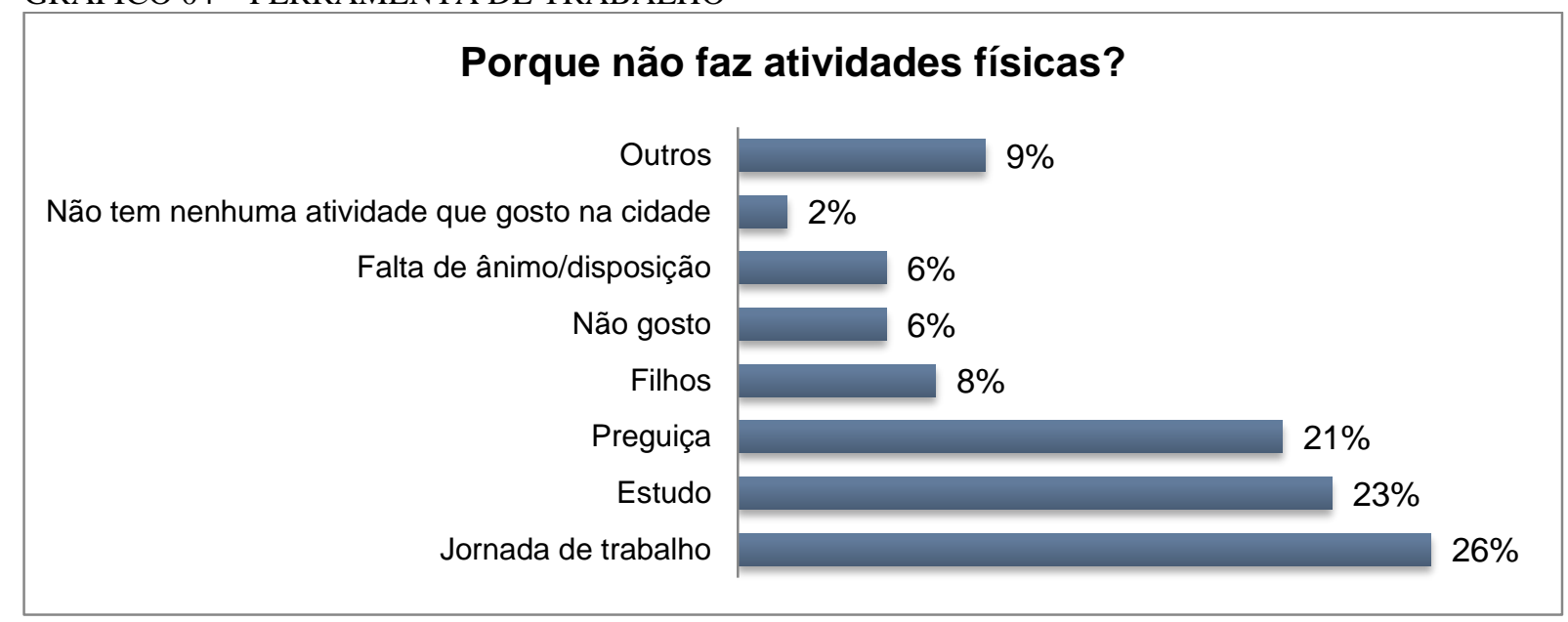

Fonte: Pesquisa de campo Vanguarda Agro S.A, 2014.

Foi verificado que $26 \%$ disse que é devido a jornada de trabalho. A academia funciona depois do horário de trabalho, pode-se perceber que os colaboradores que alegaram este motivo são cargos de confiança da empresa que não tem controle de ponto, e muitas vezes estendem o horário de trabalho.

Em segundo lugar foi levantado com $23 \%$ o estudo (faculdade), seguido de preguiça com $21 \%$ e filhos com $8 \%$.

GRÁFICO 05 - ACADEMIA MELHORARIA SUA QVT?

\section{Você acredita que frequentar academia melhoraria sua qualidade de vida no trabalho?}

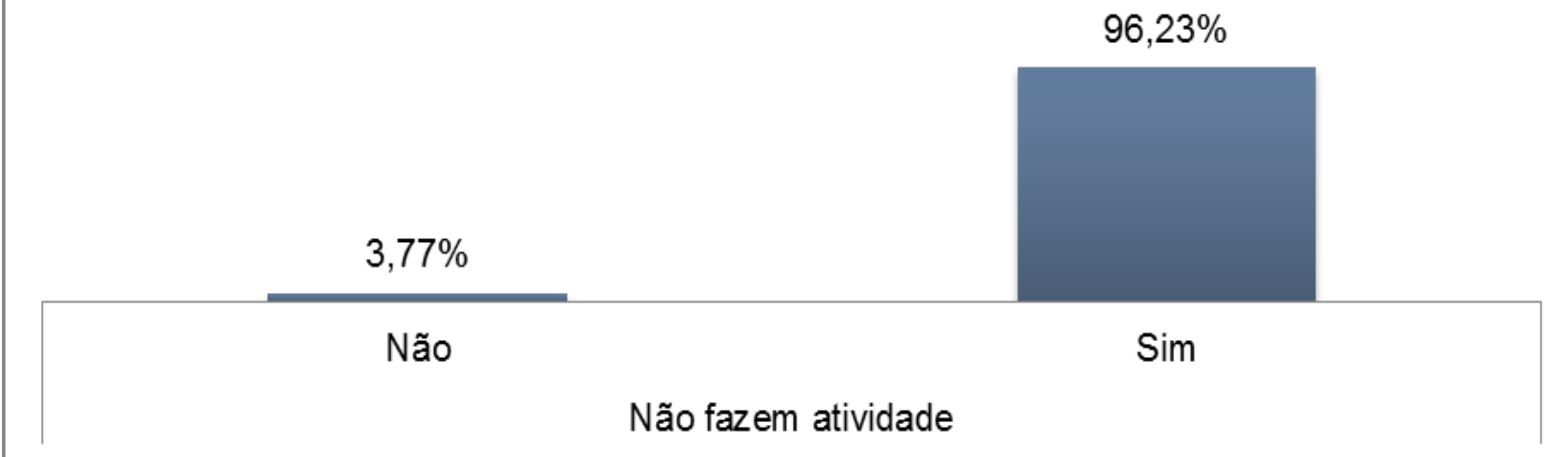

Fonte: Pesquisa de campo Vanguarda Agro S.A, 2014. 
Foi perguntado a quem faz atividades físicas se eles acreditam que praticar atividades físicas melhoraria sua QVT, onde 96,23\% respondeu que melhoraria. Desta forma, entende-se que os colaboradores que não fazem atividades tem consciência da importância dos exercícios físico sobre sua qualidade de vida, e assim as campanhas de saúde tem grandes chances de atingir seus objetivos.

Perguntou-se também o que faria com os colaboradores que não fazem atividade física fossem à academia como forma de se identificar melhorias. As principais sugestões foram horários diferenciados, aulas diferenciadas, parceiros de treino e motivação pessoal.

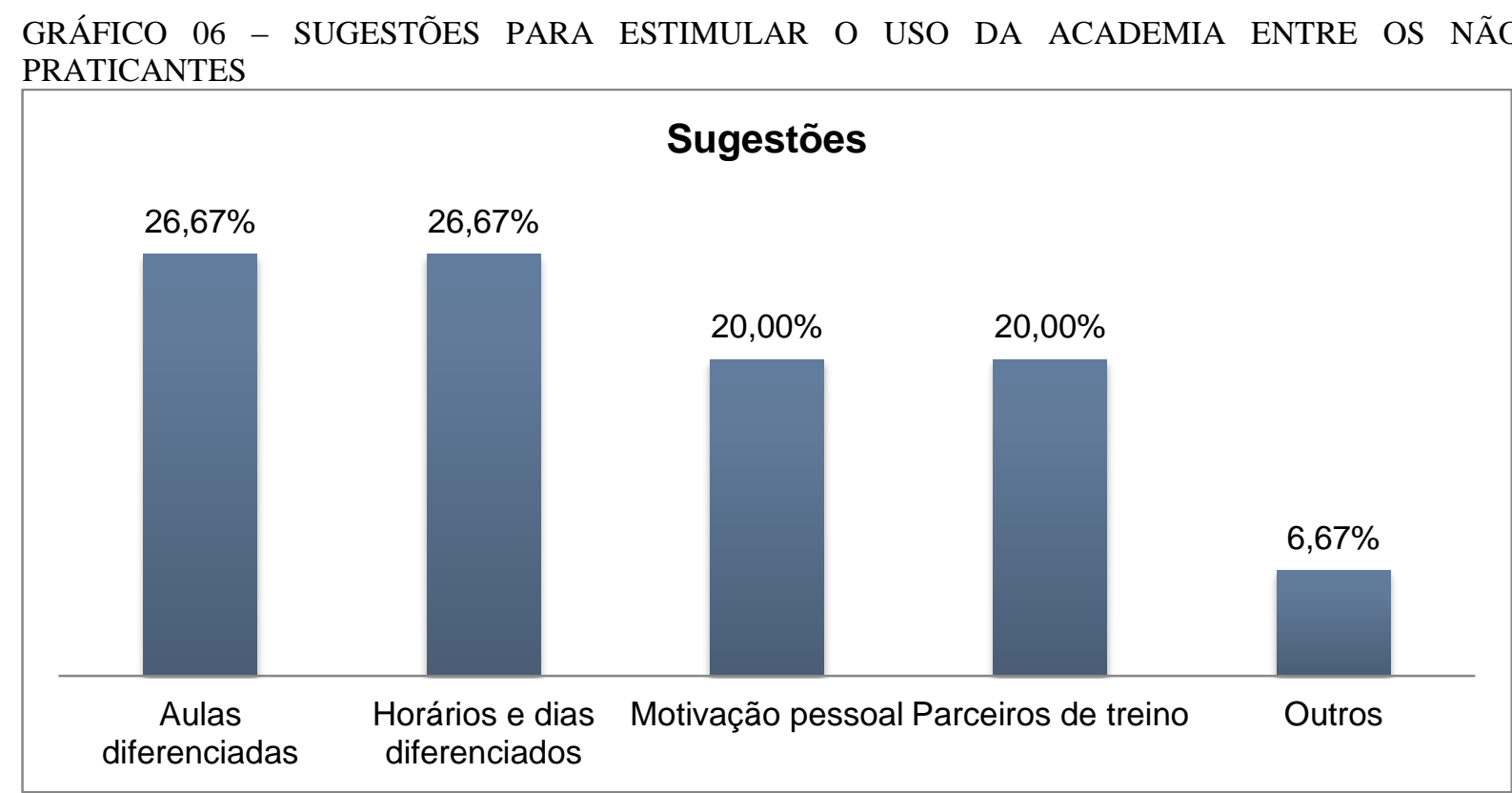

Fonte: Pesquisa de campo Vanguarda Agro S.A, 2014.

Sugere-se a empresa fazer campanhas com base nestes dados para estimular a prática de atividades físicas, tais como Campanhas de Redução de Peso com metas e premiações para aqueles que atingirem as metas, campanhas comportamentais para a escolha de hábitos diários mais saudáveis e inclusão de aulas e horários diferenciados (das 05:30 as 07:00) para atração de mais colaboradores para a academia da empresa.

\subsection{Resultados específicos dos colaboradores praticantes de atividades físicas}

Foi direcionada uma pesquisa aos que praticam atividade física para levantamento das motivações e benefícios percebidos pelos mesmos em relação aos exercícios físicos. 
GRÁFICO 07 - MOTIVOS PARA A PRÁTICA DE EXERCÍCIOS

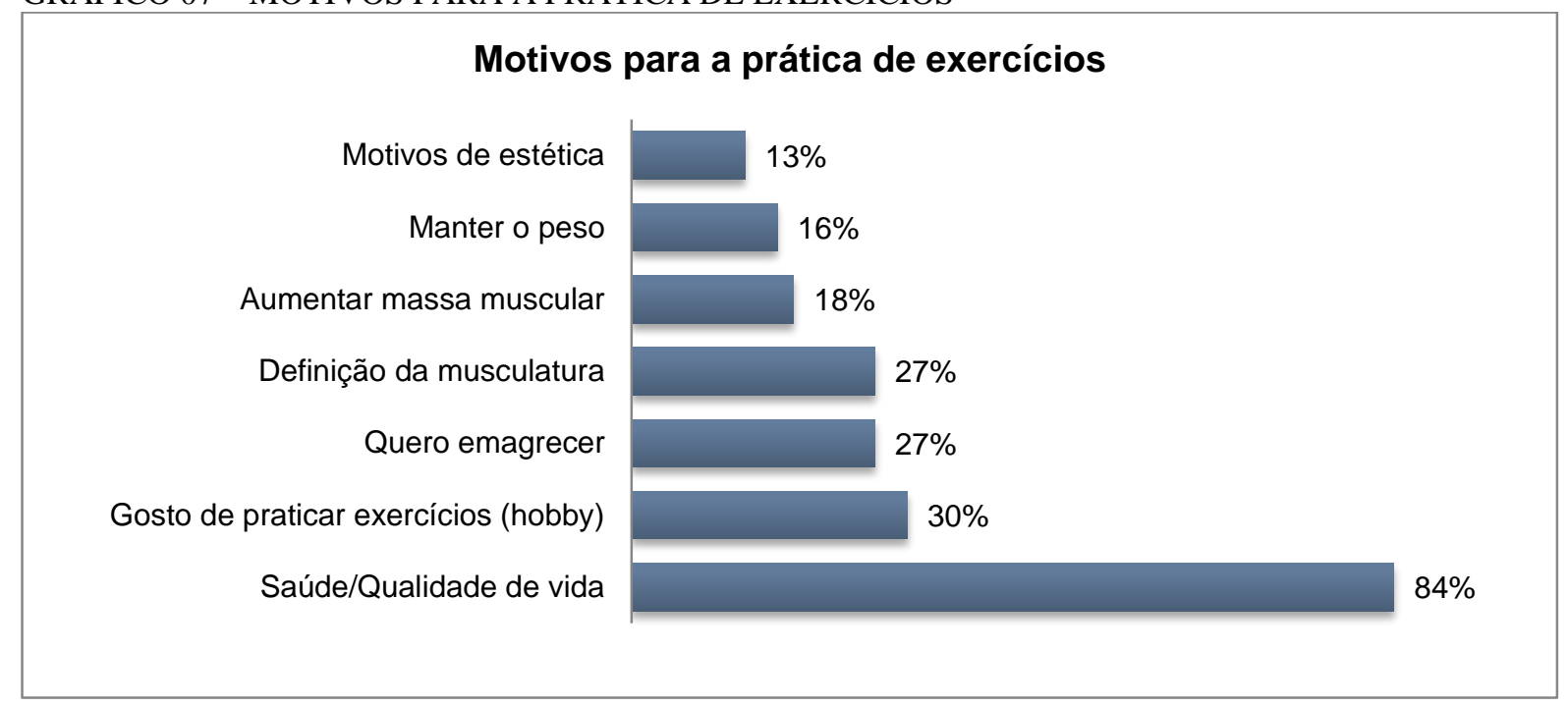

Fonte: Pesquisa de campo Vanguarda Agro S.A, 2014.

O principal motivo apontado pelos colaboradores foi a Saúde/Qualidade de Vida com $84 \%$ dos colaboradores, depois veio hobby com $30 \%$, seguido de emagrecimento com $27 \%$, definição da musculatura com $27 \%$, dentre outros.

Com relação aos benefícios da prática de exercícios físicos, conforme gráfico 08 , o principal apontado com $68 \%$ foi maior disposição para o dia-a-dia, seguido com $55 \%$ a redução do estresse, melhoria do sono com 52\%, maior autoestima com 50\%, melhoria do humor com $41 \%$, melhoria nas dores físicas com $38 \%$, redução da ansiedade com $27 \%$ e outros com $5 \%$.

Estes dados corroboram o que foi dito por Mello, Boscolo, Esteves e Tufik (2005) e Miles (2007) apud Santos \& Simões (2012) sobre os estudos a respeito dos benefícios das atividades físicas em relação a disposição, e aspectos sociais como autoestima e redução da ansiedade e estresse. 


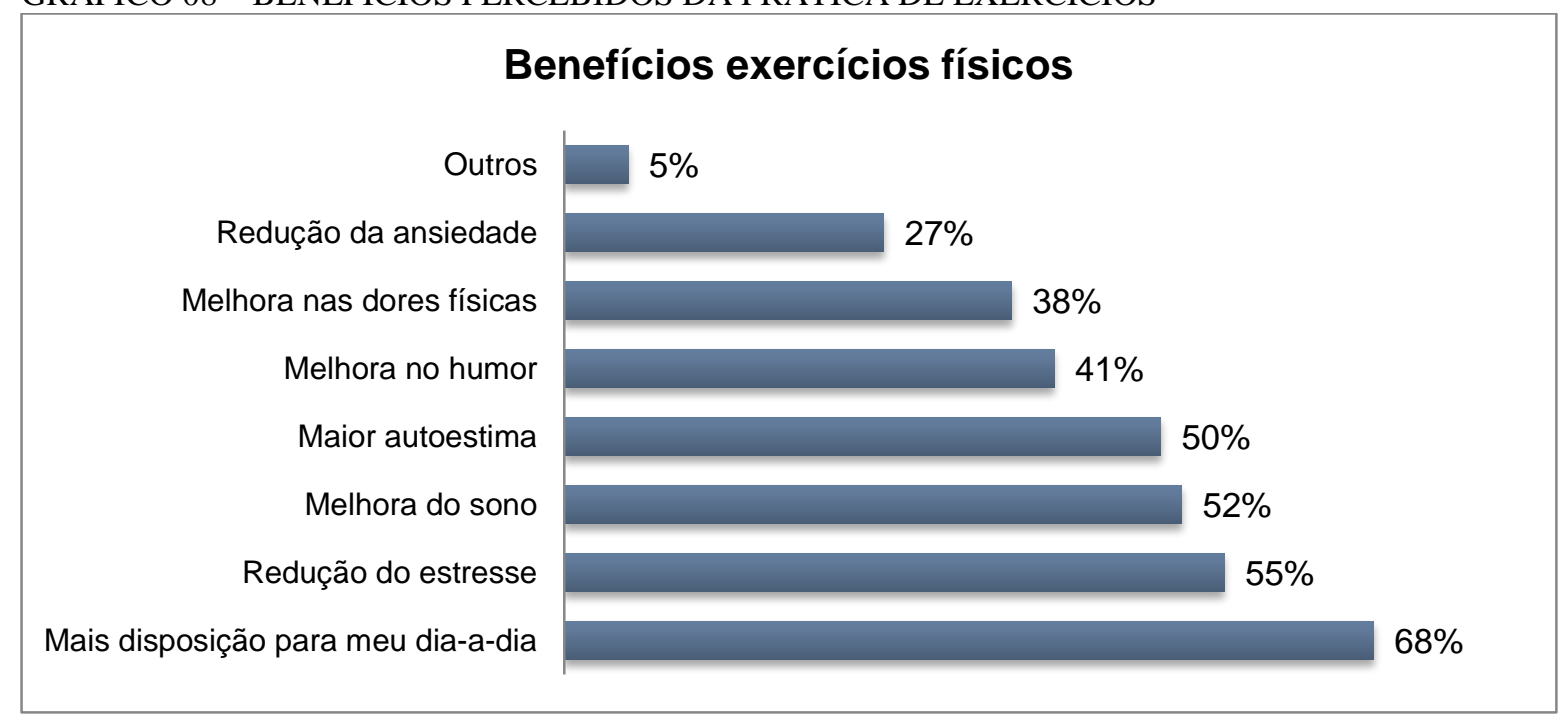

Fonte: Pesquisa de campo Vanguarda Agro S.A, 2014.

\section{CONSIDERAÇÕES FINAIS}

Analisando o resultado da pesquisa, conclui-se que a prática da atividade física regular, contribui para a melhoria da Qualidade de Vida dos colaboradores trazendo benefícios tais como: maior disposição no trabalho, redução do estresse, melhoria do sono e também das dores físicas.

Através da observação do local de trabalho, a empresa tem investido no bem-estar e saúde de seus colaboradores onde a empresa conta com: prática de ginástica laboral diária, academia dentro da empresa, equipamentos de trabalhos ergonômicos, campo de futebol e acompanhamento de profissional da área de educação física para orientação dos colaboradores.

Para melhoria da saúde e estímulo a prática de exercícios físicos, visto que 50,93\% não pratica atividades físicas, sugere-se a empresa a criação de campanhas de incentivo ao uso da academia, Campanhas de Redução de Peso, criação de horários diferenciados, aulas diferenciadas (aulas de alongamento, aulas de dança, etc.), investimento em quadras de vôlei, de areia, criação de campeonatos e torneios entre os colaboradores, para que isto atinja mais e mais.

Este artigo contribui academicamente, pois permitiu a aplicação na prática de diversos conceitos de Qualidade de Vida no Trabalho adquiridos durante o curso, desenvolvendo a capacidade de observação, a análise crítica e a habilidade de resolução de problemas.

As informações coletadas nesta pesquisa proverão a empresa inúmeras informações 
acerca da Qualidade de Vida no que tange ao bem-estar físico de seus colaboradores, servindo de subsídio para a melhoria das campanhas e da participação dos colaboradores na academia.

Sugere-se a empresa, a realização de estudos quantitativos dos colaboradores, em relação às demais condições de saúde para se agir de forma mais direcionada na melhoria do bem-estar físico e mental de seus colaboradores.

\section{REFERÊNCIAS BIBLIOGRÁFICAS}

ABC. MED.BR, 2012. Lesão por esforço repetitivo ou L.E.R.. Disponível em: $<$ http://www.abc.med.br/p/sinais. -sintomas-e-doencas/315900/lesao-por-esforco-repetitivoou-1-e-r.htm>. Acesso em: 7 set. 2014.

BARROS, M. V. e SANTOS, S. G. A atividade física como fator de qualidade de vida e saúde do trabalhador. 2005. Disponível em: < http://www.herniadedisco.com.br/espaco-drcoluna/artigos/artigo-a-atividade-fi $\% \mathrm{C} 2 \%$ Adsica-como-fator-de-qualidade-de-vida-e-saudedo-trabalhador/>. Acesso em: 7 de set. de 2014.

BOM SUCESSO, Edina. Relações interpessoais e qualidade de vida no trabalho. Rio de Janeiro: Qualitymark Ed., 2002.

BOWDITCH, James L.; BUONO, Anthony F. Elementos de comportamento organizacional. Tradução de José Henrique Lamendorf. 1. ed. São Paulo: Pioneira Thompson Learning, 2004.

CHIAVENATO, Idalberto. Gestão de Pessoas: o novo papel dos recursos humanos nas organizações. Rio de Janeiro: Elsevier, 2006.

CONTE Antonio Lázaro. Qualidade de vida no trabalho: Funcionários com qualidade de vida no trabalho são mais felizes e produzem mais. Revista FAE Business, n.7, p. 32-34, Nov. 2003. Disponível em: < http://www.ebah.com.br/content/ABAAAeiKwAG/qualiidade-viidano-trabalho>. Acesso em 24 de agosto de 2014, às 18h20min.

FIGUEIRA JUNIOR, A. J.. Atividade física na empresa: perspectivas na implantação de programas de atividade física e qualidade de vida. Revista Brasileira de Ciências da Saúde (IMES), v. 4, p. 54-58, 2004.

FOX, Edward L., BOWERS, Richard W., FOSS, Merle L. Bases Fisiológicas da Educação Física e dos Desportos. $4^{\circ}$ ed., Rio de Janeiro: Guanabara Koogan, 1991.

FRANÇA, Ana Cristina Limongi. Qualidade de vida no trabalho - QVT: conceitos e práticas nas empresas da sociedade pós-industrial. 2. ed. São Paulo: Atlas, 2004.

GRÜNSPAN, Michel. A prática de atividades físico-esportivas para profissionais do setor de serviços: um método de aprimoramento das condições psicofísicas no labor. UFSM, Dissertação de mestrado, Santa Maria, 2001.

MAXIMIANO, Antonio Cesar Amaru. Teoria geral da Administração: da revolução urbana 
à revolução global. 6. ed. São Paulo: Atlas, 2006.

MELlO, M. T.; BOSCOLO, R. A.; ESTEVES, A. M.; TUFIK, S. O Exercício Físico e os Aspectos Psicobiológicos. Revista Brasileira de Medicina do Esporte. v. 11, n. 3. p. 203207, 2005.

NAHAS Markus V. Atividade Física e Qualidade de Vida. $2^{\circ}$ ed. Londrina: Midiograf, 2001.

NETO, Jurandir A. L., Marketing de Academia. Rio de Janeiro: Editora Sprint LTDA, 1994.

SANTOS, A. L. P. ; SIMOES, A. C. . A relação entre atividade física e a qualidade de vida. Conexões (Campinas. Online), v. 10, p. 218-234-234, 2012. 